\title{
O REGISTRO PÚBLICO OBRIGATÓRIO DE ENSAIOS CLÍNICOS
}

Alguns artigos recentes, publicados simultaneamente em diversas revistas médicas importantes como New England Journal of Medicine e The Lancet, chamaram a atenção dos interessados em pesquisa clínica ${ }^{1,2}$. A pesquisa clínica é a modalidade de investigação científica de intervenção terapêutica farmacológica ou não farmacológica que envolve os seres humanos como objeto de estudos, analisando a eficácia e segurança de novos medicamentos, novas formas de tratamento cirúrgico ou de investigação diagnóstica. Resumidamente, os artigos comentam que estas revistas passarão a exigir, a partir do mês de setembro de 2005, o registro prévio de ensaios clínicos em um site norte-americano (www.clinicaltrials.gov) para que os mesmos sejam aceitos para publicação. Segundo os artigos, as revistas farão esta exigência em nome do respeito e garantia de acesso às informações por parte dos pacientes e da opinião pública. Com esta atitude, os periódicos também buscam reduzir a chance de ocorrer o viés de publicação, uma espécie de favorecimento às pesquisas com resultados positivos. Em outras palavras, trabalhos científicos cujos resultados confirmem as expectativas dos pesquisadores ou dos patrocinadores do estudo teriam maior chance de sucesso em ter seus resultados publicados. A busca do interesse do leitor pode explicar a ocorrência do viés de publicação, embora já existam algumas iniciativas em que a prioridade são as pesquisas com resultados negativos ou inesperados. $O$ acesso ao www.clinicaltrials.gov é livre e a página inicial solicita que seja feita uma inscrição individual ou coletiva, em nome de uma instituição ou empresa. O registro, totalmente em inglês, é relativamente fácil. Trata-se de uma iniciativa americana, mas já existem alguns centros canadenses e europeus inscritos, além de diversas indústrias farmacêuticas e da Organização Mundial da Saúde (OMS) ${ }^{3}$. O ponto curioso do processo, a nosso ver, é que a lista mínima de 20 prérequisitos necessários para o registro de um ensaio clínico já está preenchida praticamente na íntegra quando, no Brasil, é feita a comunicação do estudo para o CONEP. A folha de registro on-line do CONEP tem todas ou quase todas estas informações. E, ao menos teoricamente, é pública. Há algum tempo as CEPs não aceitam mais estudos clínicos que não tenham registro no CONEP, o que nos coloca na vanguarda desta iniciativa. Então por que registrar duas vezes? Pode o CONEP, no caso brasileiro, ser considerado um equivalente do registro norte-americano, a exemplo do que acontece entre Scielo e Medline? Tomando a dianteira, o corpo editorial da RAMB fomentou uma discussão sobre este assunto e recebeu opiniões de diversos pesquisadores e editores de revistas médicas brasileiras. A maior parte dos participantes concorda que o registro no CONEP deveria ser, ao menos em parte, suficiente. Foi sugerido que a CONEP se registre no www.clinicaltrials.gov como entidade mãe e inscreva todos os estudos clínicos randomizados brasileiros aprovados no site, a exemplo do que o NIH norte-americano faz. Dessa forma, pode ser evitado o duplo registro por parte do pesquisador e regularizada a situação de nossos estudos clínicos. A CONEP é uma entidade que goza de um excelente conceito internacional e não teria dificuldade de ser aceita nessa função. Foi lembrado que o British Medical Journal (BMJ) levantou alguns argumentos contrários, incluindo a dificuldade de registro nos EUA, e por isso não foi signatário da decisão, sugerindo que deve ser analisada a posição de outras revistas. Discutiu-se, ainda, se o registro deve ser necessário também para estudos publicados em revistas brasileiras. Por outro lado, foram apontadas as limitações do sistema nacional. Lembrou-se que somente 277 dos cerca de 400 CEPs existentes no Brasil estão "conectados" ao SISNEP. Além disso, se algum CEP não acusar o recebimento do projeto até 30 dias depois do registro no SISNEP, - número é cancelado. Manifestou-se algum receio com relação ao caráter público: este tipo de registro muito aberto poderia ocasionar uma perda de originalidade ou de ineditismo da pesquisa. A intenção deste editorial não é estabelecer um consenso, mas ampliar esta discussão para toda a comunidade científica brasileira. A idéias e os conceitos aqui reunidos representam a síntese de diversas opiniões manifestadas por correio eletrônico ou pessoalmente. Somente com a participação de toda a família científica nacional e das instituições envolvidas em pesquisa clínica como a CONEP, ANVISA, Secretaria de C\&T do Ministério da Saúde e a Organização Mundial da Saúde (OMS) será possível decidir - melhor caminho para as preciosas idéias nascidas, como disse um dos participantes, na terra brasilis.

Bruno Caramelli

Referências

I.De Angelis C, Drazen JM, Frizelle FA, for the International Comimittee of Medical Journals. Clinical trial registration: a statement from the International Comimittee of Medical Journals. Lancet 2004;364:9 I I-2.

2. De Angelis C, Drazen JM, Frizelle FA, Haug C, Hoey J, Horton R, et al. Is this clinical trial fully registered? A statement from the International Comimittee of Medical Journals. Lancet 2005;365: I827-9.

3. Gülmezoglu AM, Pang T, Horton R, Dickersin K. WHO facilitates international collaboration in setting standards for clinical trial registration. Lancet 2005;365: | 829-3| 